\title{
NeuroRegulation
}

\section{Avoid Zoom Fatigue, Be Present and Learn}

\author{
Erik Peper ${ }^{1 *}$, Vietta Wilson², Marc Martin ${ }^{1}$, Erik Rosegard ${ }^{1}$, and Richard Harvey ${ }^{1}$ \\ ${ }^{1}$ San Francisco State University, San Francisco, California, USA \\ ${ }^{2}$ York University, Toronto, Ontario, Canada
}

\begin{abstract}
This paper explores plausible reasons why some students report having more difficulty learning online, predominantly in Zoom synchronous classes, and suggests strategies that students can do to optimize their learning. During anonymous classroom observations, approximately $80 \%$ of 350 college students polled indicated it was harder to focus their attention and stay present while taking classes online. They also reported experiencing more isolation, anxiety, and depression compared to face-to-face classes, although much of this may be due to COVID-19 social isolation. Students often appear nonresponsive when attending online synchronous Zoom classes that negatively impacts the nonverbal dynamics of student-instructor interactions. Communication issues includes internet challenges, lack of facial expressions, body appearance, and movement. Students also report that it is more challenging to maintain attention, especially when they are multitasking. Suggested strategies are to optimize learning that includes arranging the camera so that you are visible, using active facial and body responses as if you are communicating to just one person face-to-face, configuring your body and environment (sitting upright and creating unique cues for each specific task), reducing multitasking and notifications, and optimizing arousal and vision regeneration.
\end{abstract}

Keywords: Zoom fatigue; communication; attention; learning

Citation: Peper, E., Wilson, V., Martin, M., Rosegard, E., \& Harvey, R. (2021). Avoid Zoom fatigue, be present and learn. NeuroRegulation, 8(1), 47-56. https://doi.org/10.15540/nr.8.1.47

*Address correspondence to: Erik Peper, PhD, Institute for Holistic Health Studies/Department of Recreation, Parks, Tourism and Holistic Health, San Francisco State University, 1600 Holloway Avenue, San Francisco, CA 94132. Mailing address during COVID-19: 2236 Derby Street, Berkeley, CA 94705. Email: epeper@sfsu.edu

Copyright: (๑) 2021. Peper et al. This is an Open Access article distributed under the terms of the Creative Commons Attribution License (CC-BY).
Edited by:

Rex L. Cannon, PhD, SPESA Research Institute, Knoxville, Tennessee, USA

Reviewed by:

Rex L. Cannon, PhD, SPESA Research Institute, Knoxville, Tennessee, USA

Randall Lyle, PhD, Mount Mercy University, Cedar Rapids, lowa, USA

\section{Introduction}

Overnight, the pandemic transformed college teaching from in-person to online education. Zoom ${ }^{1}$ became the preferred academic teaching and learning platform for synchronous education. Students and faculty now sat and looked at their screens for hours. While looking at their screens, the viewers were often distracted by events in their environment, notifications from smartphones, social media, and email, which promoted multitasking (Solis, 2019). The digital distractions caused people to respond to twice as many devices with half as

1 In this paper will use Zoom as the example for synchronous online teaching, although the concepts apply equally to other platforms, such Microsoft Teams and Google Meet. much attention-a process labeled semitaskingmeaning getting twice as much done half as well.

For many students synchronous online learning was more challenging, especially after teaching was shifted to a Zoom environment without adapting the course materials to optimize online learning. During polling of 325 undergraduate university students at a metropolitan university who were all taking synchronous online Zoom classes, the vast majority reported that learning was somewhat to extremely difficult, with only the minority of students (approximately 6\%) preferring online learning, as shown in Figure 1.

The increased self-report on difficulty experienced in synchronous Zoom online learning may also affect 


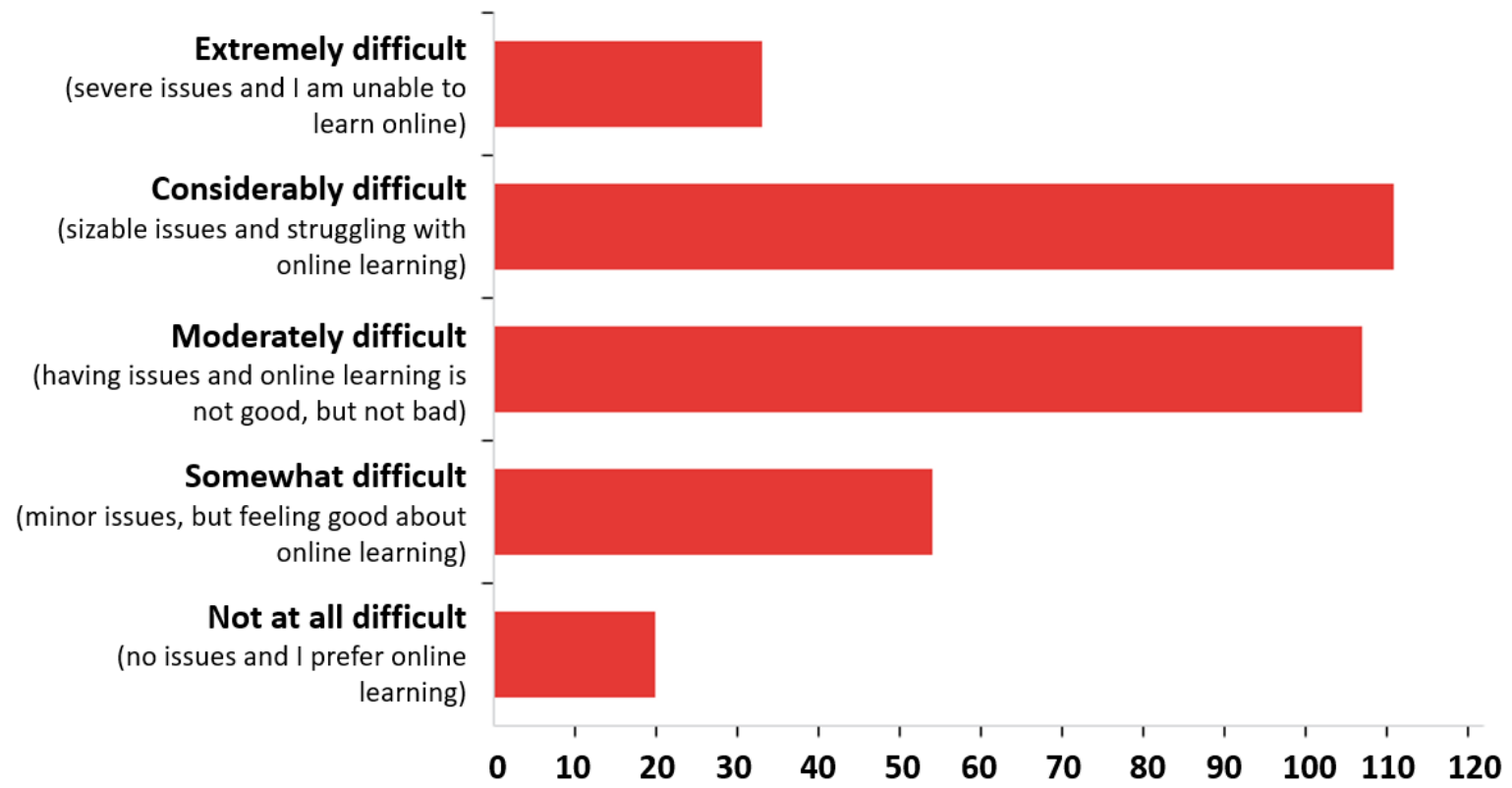

Figure 1. Survey of 325 Undergraduates comparing Zoom online learning compared to the previous in-person classes. Approximately $94 \%$ had moderate to considerable difficulty with online learning.

academic achievement. Kuhfeld et al. (2020) reported that there appears to be a significant loss in learning gains for reading and mathematics compared to a typical school year for junior and senior high school students. The actual reduction in academic achievement may depend upon multiple factors such as access to internet and computer and social support. At the same time, many people have reported an increase in physical, behavioral, and psycho-emotional problems; for example, backache, headache, stomachache, eyestrain, sore neck and shoulder pain, over- or undereating, over- or undersleeping, over- or underexercising, ruminative thoughts related to categories of anxiety or fear, boredom or numbness, depression or sadness, anger or hostility, etc. (Fosslien \& Duffy, 2020; Intolo et al., 2019; Lee, 2020; Leeb et al., 2020; McGinty, Presskreischer, Anderson, Han, \& Barry, 2020; Peper \& Harvey, 2018; Peper, Harvey, \& Faass, 2020).

This paper explores differences in communication and factors that can enhance learning during synchronous Zoom online education. The concepts are derived from our teaching athletes to sustain peak mental and physical performance, with the implication that the same concepts can help students towards sustaining on-topic attention during online learning (Wilson \& Peper, 2011). In sports, the coach can help guide the athlete; however, the athlete needs to be present and motivated. Faculty have a responsibility to support, encourage, and engage students, while students have the responsibility to configure themselves into an optimum learning state.

\section{Differences in Communication Between Live and Computer Communication}

Until the 20th century, almost all communication included nonverbal expressions. The speaker used verbal and nonverbal expressions, while the respondent would immediately show a reaction to the speaker. There was a continuous dynamic verbal and nonverbal exchange. The listener would respond to the speaker. If listeners agreed, they nodded their heads. If they disagreed or were intimidated, they would provide alternative body movements (e.g., shake their head) or facial expressions (e.g., look away or frown).

During normal conversations, both the speaker's facial expression and body language are noticed and responded to, which in turn can be used as feedback by the other person. Although Zoom, Microsoft Teams, or Google Meet provide dynamic visual and auditory feedback, especially in a one-tofew session, in large group sessions with many participants, the visual feedback is reduced and facial responses are difficult to distinguish, especially when in Gallery view.

In a Zoom environment, both the sender and receiver are watching the computer screen without awareness that nonverbal cues are essential for the 
purpose of understanding not only what is being said but also for the implied meaning and its importance.

These nonverbal cues are usually processed without awareness in live person-to-person exchange. While sending and receiving are usually simultaneous, there can exist a disconnect between the attached meanings of the encoded information and that of the decoded information due to the inconsistent existence of important nonverbal components. In a Zoom environment, the end result could mean multiple images of receivers providing the sender with little or no nonverbal cues with which to interpret the meaning they have attached to the presenter's message. The audience may appear to look at him; however, he does not know whether they are attending to him, have a neurological disorder and cannot respond, are reading their emails, watching YouTube videos, or texting on their phone. Additionally, the nonverbal cues they are sending may not be related to his message but rather to their reaction to other media, people, or distractions not seen by the presenter.

This mode of communication is different from communication patterns that through natural selection have allowed the human species to thrive and survive. For the first time in human history we learn, teach, work, socialize, and entertain in front of the same screen. In many cases, communication in the era of smartphones has been reduced to texting, writing digital responses, or reacting to media content on any screen. Over the past few decades, it is possible for people to communicate through more disembodied, off-topic, and external modes of interaction. So many types of learning activities vie for our attention and can occur without leaving our chairs; thus, it may be difficult to stay on-topic in online Zoom classes (Keller, Davidesco, \& Tanner, 2020).

Normal communication typically involves whole body movements (face, head, arms, and hands) which tends to energize or sometimes distract the speaker or listener (Kendon, 2004). When communicating with friends, we often move our bodies dynamically and responsively during the discussion. With synchronous large online lectures, students tend to be passive and just sit and watch. ${ }^{2}$ This state of sitting and just watching the screen is similar to

\footnotetext{
2 Zoom and other synchronous online platforms provide tools to indicate that you would like to speak (e.g., electronic hand raising); however, it is an issue of how the class session is designed (e.g., do you use breakout rooms, are there structured requests for interaction).
}

watching video entertainment where we sit for a long time and are covertly conditioned not to act. Thus, we have trained ourselves not to initiate action since the screen does not provide feedback to our responses-a process so different from talking and responding spontaneously in groups of participants. For many students it is more challenging to respond in an online large group, as the person becomes the focus of the group and sometimes is self-conscious and concerned about what others will think of them.

When communication is safe, people interact, respond, and chime in. In large groups, just like in large lectures, Zoom tends to inhibit this process because it delays social feedback since most people mute their microphones to avoid extraneous noise. This is usually the rule for large groups; in small groups, people often unmute themselves. The physical act of unmuting is an additional barrier to spontaneous verbal responses. This shift of attention induces a delay before responding. From a communication perspective, a delay before responding reduces the spontaneity and is often interpreted more negatively by the listener (Roberts, Margutti, \& Takano, 2011).

\section{Facial Expressions and Auditory Processing}

Facial expressions are a critical part of nonverbal feedback, signaling to the other person that they are being listened to and providing cues that the interaction is safe. We unknowingly react to facial expressions-processed unconsciously through neuroception (Porges, 2017) - to indicate whether the person is signaling safety or danger. Usually when the person's facially responsiveness shows expression, it signals safety and allows communication and intimacy to be developed. If the person shows no facial expressions (a still/flat face), we unconsciously interpret this as a signal of danger (Porges, 2017). The importance of responsive feedback is illustrated in the study by Tronick, Adamson, Als, and Brazelton (1975), where mothers were instructed not to respond with facial and body cues to their infant. The babies rapidly became highly disturbed when the mother stayed nonresponsive, as dramatically illustrated in the YouTube video, Still Face Experiment: Dr. Edward Tronick (Tronick, 2009). In adults, lack of verbal and nonverbal feedback during social evaluations is extremely stressful (Birkett, 2011; Gruenewald, Kemeny, Aziz, \& Fahey, 2004). This response is the basis of the Trier Social Stress Test (TSST) that many researchers use to explore the effect of social stress (Allen et al., 2016). The TSST requires a person to prepare a presentation, deliver a speech, and verbally respond to a challenging arithmetic 
problem in the presence of judges who show no emotional and nonverbal responses (Kirschbaum, Pirke, \& Hellhammer, 1993).

The absence of social facial and body feedback often makes teaching and learning more challenging. Namely, are the receivers-the invisible (only their picture or name is shown), partially visible (facial features are indistinct due to backlighting), or ghosting (those whose picture and name are shown but are physically absent from the session)-understanding the information the way the sender intended? Unlike traditional classroom settings where one has the benefit of seeing and sensing nonverbal cues, often in the Zoom Gallery view the speaker may not know what how the audience is responding and this contributes to Zoom fatigue. In addition, the communication bond is often reduced when the speaker does not look at the audience and the listener does not respond to the speaker with facial expressions. Zoom fatigue can also be reduced when online teaching tools are used appropriately by involving active feedback responses through polls, chat, etc. as well as by asking specific participants to speak and give feedback.

What is unique to the synchronous online environment is that the speakers and participants view themselves. This is the first time in human history that people are seeing themselves while speaking. ${ }^{3}$ For some people, seeing themselves may increase anxiety and negative self-judgementa process that is even more prevalent in teens. Some are self-conscious, and some have social anxiety and do not want their face to be shown (Degges-White, 2020). In the past, most of us had no idea how we looked when we were communicating -it is totally novel experience to see yourself while talking and communicating.

\section{Reduced Physical Activity and Increased Near Vision Stress}

Before sheltering in place, I would walk from my house to the BART station, take the train to Daly City station, and then walk to the university. At the university, I would climb stairs to go to my office, meet with other faculty, and walk to the classroom. At the end of the day, I would walk

\footnotetext{
${ }^{3}$ Zoom has a feature to hide yourself when you start or join a Zoom meeting. The meeting automatically begins in Speaker View, where you can see your own video. Rightclick your video to display the menu, then choose Hide Myself.
}

back to the Bart station and eventually walk home. Without any thinking or trying to do any exercise, I usually would do 12,000 steps and about 25 stairs. Now, I am lucky if I do 3,000 unless I will myself to do more exercise.

The move to a Zoom environment and sheltering in place means that we sit more and more, which tends to increase mortality, decrease subjective energy, and contribute to an attitude of passive engagement, more as an observer than as a participant (Oswald, Rumbold, Kedzior, \& Moore, 2020; Patel, Maliniak, Rees-Punia, Matthews, \& Gapstur, 2018; Stamatakis et al., 2019; Yalçin, Özkurt, Özmaden \& Yagmur, 2020). While sitting, we also tend to slouch as we look at the screen that may be a covert factor in the increasing rates of depression and anxiety. This slouching position tends to decrease access to positive memories and allow easier access to negative memories (Peper, Lin, Harvey, \& Perez, 2017) as well as interfere with academic performance. Peper, Harvey, Mason, and Lin (2018) found that students have more difficulty performing mental math in the slouched as compared to upright sitting position. To reduce the impact of sitting, Peper and Lin (2012) found that when students perform some physical activities (e.g., skipping in place) for just a minute they report significantly increased subjective energy and attention levels.

When looking at the screen our eyes only focus on the screen, which is different from in-person communication where you look at the person and then look behind or to the side of the person. Only focusing at the screen requires the muscles of the eyes to tighten for the eyes to be able to converge and the ciliary muscles around the lens contract so that the lens curvature is increased, resulting in near visual stress. This continuous looking at a near object is different from normal eye function in which we alternately focus on nearby objects and then look far away, which allows the muscles of the eyes to relax.

\section{Student Issues}

Factors that contributed to negative experiences of pandemic distance learning included obvious concerns such as social isolation, challenges with maintaining attention during distance learning classes, as well as uncontrollable disruptions and related technical issues (e.g., limited $\mathrm{Wi}-\mathrm{Fi}$, inadequate bandwidth or appropriate computer power). Typical negative experiences included reports of having little or no control over technical issues or the necessity of distance learning formats. 
They also reported a lack of control related to job loss or receipt of any financial support to deal with income loss. A third common report included lack of a private workspace at home. Together, ruminations about various negative experiences plus lack of privacy resulted in reduced attention, especially when others in the household caused disruptions of the learning space or disruptions to other scheduled daily activities. In addition, the perceptions of loneliness may have resulted from the de facto isolation imposed by shelter-in-place pandemic policies (Jelaca, Anastasovski, \& Velickovska, 2020; Lemay, Doleck, \& Bazelais, 2019).

Numerous students reported that it was much easier to be distracted and multitask, check Instagram, Facebook, and TikTok, or respond to emails and texts than during face-to-face classroom sessions as illustrated by two students' comments.

"Now that we are forced to stay at home, it's hard to find time by myself, for myself, time to study, and or time to get away. It's easy to get distracted and go a bit stir-crazy."

"I find that online learning is more difficult for me because it's harder for me to stay concentrated all day just looking at the screen."

Students often reported that they had more difficulty remembering the materials presented during synchronous presentations. Most likely, the passivity while watching Zoom presentations affected the encoding and consolidation of new material into retrievable long-term memory. The presented material was rapidly forgotten when the next screen image or advertisement appeared and competed with the course instructor for the students' attention. We hypothesize that the many hours of watching TV and streaming videos have conditioned people to sit and take in information passively, while discouraging them to respond or initiate action (Mander, 1978; Mărchidan, 2019). Learning requires engagement, which means a shifting from passively watching and listening to being an active participant shareholder in synchronous online classes. However, in most cases, students have not received information, education, or training on how to be a more active and engaged participant in a synchronous Zoom class.

\section{Instructor Issues}

Instructors also have many of the same issues when presenting classes online. They engage in multiple simultaneous roles: presenter, director, and producer. While teaching, they need to engage students, monitor the chat for feedback, and look at the screen for facial responses. At the same time, they may face similar technical issues as those experienced by students such as internet connectivity, limited bandwidth, and mastering the technical features of synchronous online learning technology. At times, instructors feel that students expect each presentation to be as captivating as a TED Talk. Thus, teaching has shifted from education to edutainment.

\section{Practical Suggestions to Optimize Learning}

To optimize learning in the synchronous online environment, teachers have the responsibility to reconfigure their teaching so that it incorporates active student involvement, and students have the responsibility to be present and engaged. The following practices may facilitate learning.

\section{Be Present to Learn}

Mastering media presence is becoming even more important for everyone. The skill implemented in attending an online learning class will also be useful for professional development. Although the pandemic shifted personal interviews to online interviews, most likely synchronous and asynchronous video interviews will be part of the first automatic screening level to assess candidates for a job (Rubinstein, 2020).

Be visible for the other person looking at you to create a positive impression. Adjust your camera and lights so that your face is visible and you are looking at the person to whom you are talking. Your screen presence is representing you. Does the camera show you engaged, distracted, or lying in bed? Be aware that you and your background together create an impression. The concept of looking directly at the audience-looking directly at the camera-is not new. Everyone working in media (newscasters, politicians, actors) have been trained to make their faces visible and expressive. This means arranging your webcam at eye level right in front of you and speaking to the camera as if it is the person. Avoid looking down at the person on the screen since the viewer would see you looking look down and away. Be sure your face is illuminated and there are no bright light sources behind you (Purdy, 2020). We recommend that, in a small group, participants unmute their microphones so that people can respond spontaneously to each other unless there is excessive background noise. 
Be a responsive and interactive listener to configure your brain to be engaged. Shift from being a passive absorber to an active participant, even if your camera is off or the speaker cannot see you. Imagine being physically with the speaker and activate yourself by increasing your face and body animation as you are attending a synchronous online class. Thus, when you watch a presentation, act as if you are in a personal conversation with the presenter or the material. This means that if you agree, nod your head; if you disagree, shake your head (do this naturally without making it a work task). Do this for the whole session. Our research has shown that when college students purposely implement animated facial and body responses during Zoom classes, they report a significant increase in energy level, attention, and involvement as compared to just attending normally in class (Peper \& Yang, in press; see Figure 2).

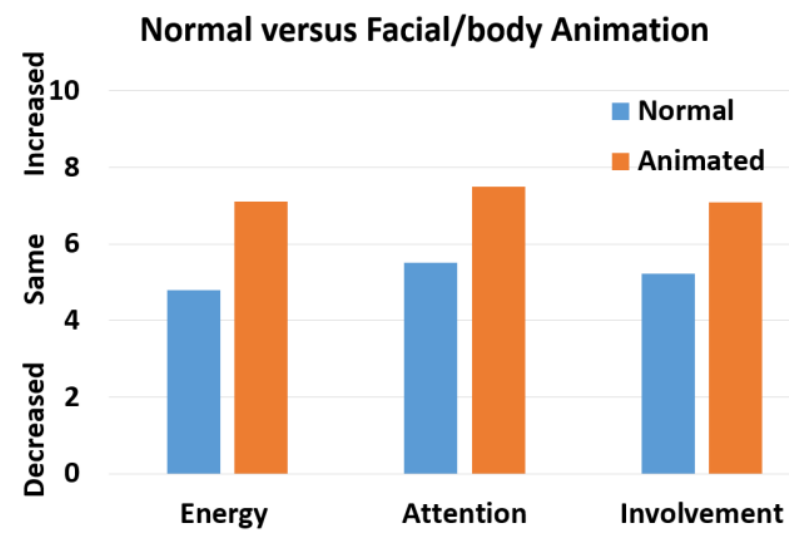

Figure 2. Change in subjective energy, attention and involvement when the students significantly increase their facial and body animation by $123 \%$ as compared to their normal nonexpressive class behavior.

"I never realized how my expressions affected my attention. Class was much more fun." -22-year-old female student

"I can see how paying attention and participation play a large role in learning material. After trying to give positive facial and body feedback, I felt more focused and I was taking better notes and felt I was understanding the material a bit better."

-28-year-old medical student
Configure your body to attend and perform. Sit upright and adapt a position of empowerment. When we sit upright and expanded, it is easier to have positive thoughts and detach from negative hopeless thoughts (Peper, Harvey, Mason, \& Lin, 2018; Peper, Lin, Harvey, \& Perez, 2017). Students also performed better in mental math when they sat upright as compared to collapsed. When students are provided ongoing feedback when they begin to slouch by an app that uses the computer camera to monitor slouching, they reported a significant decrease in neck and back symptoms (Chetwynd, Mason, Almendras, Peper, \& Harvey, 2020). As one of many students reported:

"Before, when I didn't use the app, I had lots of shoulder and neck pain. Now when I use it, the pain went way down as I kept changing posture to the feedback signal. I had more energy and I was more alert. I did notice that when I would get the alert to sit up straight."

\section{Optimize Concentration and Learning}

In the online environment, the structure more likely depends upon the person, unlike the externally created structure of going to work or to class. Thus, purposely creating a time structure and scheduled time periods to perform different tasks as time management skills are associated with improved school and work performance (Macan, Shahani, Dipboye, \& Phillips, 1990). Create an environment to promote concentration and reduce distractions.

Stay on task and reduce interruption and practice refocusing on task. On the average we now check our phones 96 times a day-that is once every 10 minutes and an increase of $20 \%$ as compared to two years ago (Asurion, 2019). Those who do media multitasking, such as texting while doing a task, perform significantly worse on memory tasks than those who are not multitasking (Madore et al., 2020). Multitasking is negatively correlated with school performance (Giunchiglia, Zeni, Gobbi, Bignotti, \& Bison, 2018). When working or attending a class or meeting, turn off all notifications (e.g., email, texts, and social media), and then block out specific times when you work on Zoom and when you respond to email, phone, or social media (Newport, 2016). Let people know that you will look at the notifications and respond in a predetermined time so that you will not be interrupted while working or studying. If you work where there are other people, arrange your workstation so that there are fewer distractions, such as sitting with your back to other people. When students chose to implement a behavior change to monitor cell phone and media 
use and to reduce the addictive behavior during a 5week self-healing project, many report a significant improvement of health and performance. One student observed that when she reduced her cell phone use, her stress level equally decreased as shown in Figure 3.

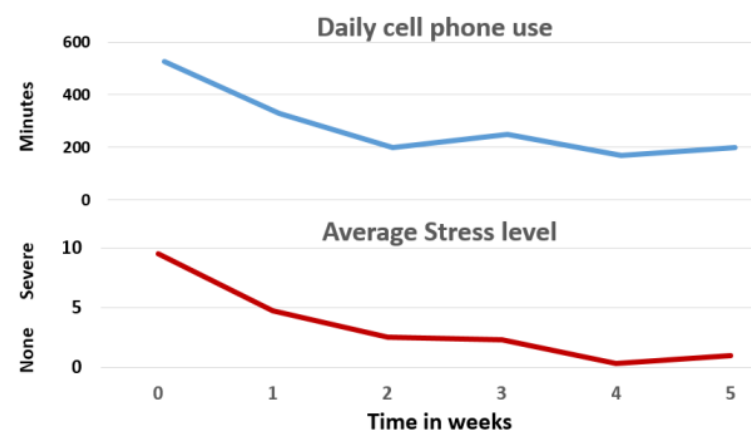

Figure 3. Example of a student changing cellphone use and corresponding decrease in subjective stress level.

During this class project, many students observed that continuous responding to notifications and social media affects their health and productivity. As one student reported,

The discovery of the time I wasted giving into distractions was increasing my anxiety, increasing my depression, and making me feel completely inadequate. In the 5-week period, I cut my cell phone usage by over half, from 32.5 $\mathrm{hr}$ to exactly $15 \mathrm{hr}$, and used some of the time to do an early morning run in the park. Rediscovering this time makes me feel like my possibilities are endless. I can go to work full time, take online night courses reaching towards my goal of a higher degree, plus complete all my homework, take care of the house and chores, cook all my meals, and add reading a book for fun!

-22-year-old college student

Approach learning with a question. When you begin to study the material or attend a class, ask yourself questions that you would like answered. If possible, put your questions to the instructor. When you have a purpose, it is easier to stay emotionally present and remember the material (Osman \& Hannafin, 1994).

Take written notes while attending a Zoom meeting or class. When participants take handwritten notes versus on the computer, they tend to integrate and remember the material much more than just watching passively (Mueller \& Oppenheimer, 2014). Active note-taking leads to focused attention and fewer distractions from social media content (Flanigan \& Titsworth, 2020).

Review materials. At the end of the class, meet with your fellow students on Zoom or social media and review the class materials. As you discuss the materials, add comments to your notes and, if possible, do a hierarchical outline to more easily remember the relationships among the ideas.

Change your internal language. What we overtly or covertly say and believe is what we may become. When one says, "I am stupid," "I can't do math," or "It is too difficult to learn," one may feel powerless, which increases stress and inhibits cognitive function. Instead, change the internal language so that it implies that you can master the materials such as, "I need more time to study and to practice the material," "Learning just takes time, and at this moment it may take a bit longer than for someone else," or "I need a better tutor."

Create an Environment to Trigger the Appropriate Mental and Emotional State for Learning

Learning and recall are state dependent. Without awareness, the learned content is covertly associated with environmental, emotional, social, and kinesthetic cues. Thus, when you study in bed, the material is more easily accessed while lying down. When you study with music, the music becomes a retrieval cue. Without awareness, the materials are encoded with the cues of lying down or the music played in the background. When you take your exam in a different setting then you have studied, none of the covert cues are there; thus, it is more difficult to recall the material. Study and review the materials under similar conditions as where you will be tested.

To configure yourself to be ready to study, work, or socialize, create different environments that are unique to each category of Zoom involvement (studying, working, socializing, entertaining). PreCOVID, we usually used different clothing for different events (work vs. party) or different environments for different tasks (temple, churches, mosques, or synagogue for religious practice; bar or coffee shop to meet friends). Create a unique environment with each Zoom activity. The stimuli to be associated to the specific tasks can also include lighting, odors, sound, or even drinks and food. These stimuli become the classically conditioned cues to evoke the appropriate response associated 
with the task, just as Pavlov conditioned dogs to salivate by pairing a sound with the meat. Taking charge of the conditioning process may help many people to focus on their tasks, as so many students use their bedroom, kitchen, or living room for Zoom work, which is not always conducive for learning or work.

Wear task-specific clothing just as you would have done going to work or school. When you plan to study, put on your study T-shirt. In time, the moment you put on the study T-shirt, you are cueing yourself to focus on studying. When finishing with studying, change your clothing.

Arrange task-specific backgrounds for each category of Zoom task. Place a different background such as a poster or wall hanging behind the computer screen-one for studying and another for entertainment. When finished with the specific Zoom event, take down the poster and change the background.

\section{Optimize Arousal and Regenerate Vision}

The longer we sit the more passive we tend to become. Teachers will benefit by interrupting the passive transfer of information by guiding students in fun short movements to increase arousal. If instructors fail to put in movement breaks, students sitting in front of screens can remind themselves to move. The challenge is that we are usually unaware of how much time has passed as we are captured by the screen. It is often helpful to use an app such as StretchBreak ${ }^{4}$ to remind yourself to get up and move.

Get up and move every $\mathbf{3 0}$ min. After sitting for a 30-min stretch, wiggle and move. Do the movements with vigor or even dance, look up and reach up. When you stand up and move your legs and feet, you tighten and relax your calf muscles that pump the venous blood and lymph fluids that have been pooling in your legs back to your heart. The calf muscle is often called the second heart because in facilitates venous blood return.

Regenerate vision. Our eyes tend to get tired, and then the world looks blurry. Interrupt the near vision stress by allowing the eyes to relax and regenerate.

- Palming. Bring your hands to your face and cup the hands so that there is no pressure on your eyeballs. Allow the base of the hands to touch the cheeks while the fingers are interlaced

\footnotetext{
${ }^{4}$ Free app available from http://www.stretchbreak.com
}

and resting your forehead. Then, with your eyes closed, imagine seeing black. Breathe slowly and diaphragmatically while feeling the warmth of the palm soothing the eyes. Feel your shoulders, head, and eyes relaxing, and do this for 5 min (Peper, 2021; Schneider, 2016).

- Look at the distance. Interrupt near visual stress (convergence of the eyes and tightening of the ciliary muscle around the lens allows us to focus on the screen) by looking away at the far distance. Every so often look at the clouds, tops of trees, or rooftops outside the window to relax the eyes.

\section{Summary}

By activating the evolutionary communication patterns that allowed us to survive and thrive and using known performance enhancement skills derived from peak performance training, we can enhance involvement and productivity. The instructor needs to stay current on methods that keep students' attention. At the same time, students have a responsibility to configure themselves to optimize learning. We recommend practices to (1) be present and learn, (2) optimize concentration and learning, (3) create an environment to trigger the appropriate mental and emotional state for learning, and (4) optimize arousal and regenerate vision. By taking charge of your own teaching or learning process and configuring yourself to be present through active participation, learning is enhanced.

\section{Author Note}

We thank Professor Jackson Wilson for his incisive comments.

\section{Author Disclosure}

Authors have no grants, financial interests, or conflicts to disclose.

\section{References}

Allen, A. P., Kennedy, P. J., Dockray, S., Cryan, J. F., Dinan, T. G., \& Clarke, G. (2016). The Trier Social Stress Test: Principles and practice. Neurobiology of Stress, 6, 113-126. https://doi.org/10.1016/j.ynstr.2016.11.001

Asurion. (2019, November 21). Americans check their phones 96 times a day [Press release]. https://www.asurion.com/about /press-releases/americans-check-their-phones-96-times-aday/ - : :text=Despite our attempts to curb,tech care company Asurion1.

Birkett, M. A. (2011). The Trier Social Stress Test protocol for inducing psychological stress. Journal of Visualized Experiments: JoVE, (56), e3238. https://doi.org/10.3791/3238

Chetwynd, J., Mason, L. A., Almendras, M., Peper, E., \& Harvey, R. (2020, December). Posture awareness training. Poster presented at the 51st Annual Scientific Meeting of the 
Association for Applied Psychophysiology and Biofeedback, online. https://doi.org/10.13140/RG.2.2.20194.76485

Degges-White, S. (2020, April 13). Dealing with Zoom anxiety. Psychology Today. https://www.psychologytoday.com/us/blog /lifetime-connections/202004/dealing-zoom-anxiety

Flanigan, A. E., \& Titsworth, S. (2020). The impact of digital distraction on lecture note taking and student learning. Instructional Science, 48, 495-524. https://doi.org/10.1007 /s11251-020-09517-2

Fosslien, L., \& Duffy, M. W. (2020, April 29). How to combat Zoom fatigue. Harvard Business Review. https://hbr.org/2020 /04/how-to-combat-zoom-fatigue

Giunchiglia, F., Zeni, M., Gobbi, E., Bignotti, E., \& Bison, I. (2018). Mobile social media usage and academic performance. Computers in Human Behavior, 82, 177-185. https://doi.org /10.1016/j.chb.2017.12.041

Gruenewald, T. L., Kemeny, M. E., Aziz, N., \& Fahey, J. L. (2004). Acute threat to the social self: Shame, social self-esteem, and cortisol activity. Psychosomatic Medicine, 66(6), 915-924. https://doi.org/10.1097/01.psy.0000143639.61693.ef.

Intolo, P., Shalokhon, B., Wongwech, G., Wisiasut, P., Nanthavanij, S., \& Baxter, D. G. (2019). Analysis of neck and shoulder postures, and muscle activities relative to perceived pain during laptop computer use at a low-height table, sofa and bed. Work, 63(3), 361-367. https://doi.org/10.3233/WOR192942

Jelaca, M., Anastasovski, I., \& Velickovska, L. A. (2020). A report on the impacts of the coronavirus SARS-CO-2 "shelter-inplace order" on fitness and well-being. Research in Physical Education, Sport and Health, 9(1), 13-18. https://doi.org /10.46733/PESH2090013j

Keller, A. S., Davidesco, I., \& Tanner, K. D. (2020). Attention matters: How orchestrating attention may relate to classroom learning. CBE-Life Sciences Education, 19(3), fe5. https://doi.org/10.1187/cbe.20-05-0106

Kendon, A. (2004). Gesture: Visible action as utterance. Cambridge, England: Cambridge University Press.

Kirschbaum, C., Pirke, K.-M., \& Hellhammer, D. H. (1993). The 'Trier Social Stress Test'-A tool for investigating psychobiological stress response in a laboratory setting. Neuropsychobiology, 28, 76-81. https://doi.org/10.1159 1000119004

Kuhfeld, M., Soland, J., Tarasawa, B., Johnson, A., Ruzek, E., \& Liu, J. (2020). Projecting the potential impact of COVID-19 school closures on academic achievement. Educational Researcher, 49(8), 549-565. https://doi.org/10.3102 $10013189 \times 20965918$

Lee, J. (2020, November 17). A neuropsychological exploration of Zoom fatigue. Psychiatric Times. https://www.psychiatrictimes.com/view/psychologicalexploration-zoom-fatigue

Leeb, R. T., Bitsko, R. H., Radhakrishnan, L., Martinez, P., Njai, R., \& Holland, K. M. (2020). Mental health-related emergency department visits among children aged $<18$ years during the COVID-19 pandemic-United States, January 1-October 17, 2020. Morbidity and Mortality Weekly Report (MMWR), 69(45), 1675-1680. /mmwr.mm6945a3

Lemay, D. J., Doleck, T., \& Bazelais, P. (2019). Selfdetermination, loneliness, fear of missing out, and academic performance. Knowledge Management \& E-Learning: An International Journal, 11(4), 485-496. https://doi.org /10.34105/j.kmel.2019.11.025

Macan, T. H., Shahani, C., Dipboye, R. L., \& Phillips, A. P. (1990). College students' time management: Correlations with academic performance and stress. Journal of Educational Psychology, 82(4), 760-768. https://doi.org/10.1037/00220663.82.4.760

Madore, K. P., Khazenzon, A. M., Backes, C. W., Jiang, J., Uncapher, M. R., Norcia, A. M., \& Wagner, A. D. (2020).
Memory failure predicted by attention lapsing and media multitasking. Nature, 587, 87-91. https://doi.org/10.1038 /s41586-020-2870-z

Mander, J. (1978). Four arguments for the elimination of television. New York, NY: William Morrow Paperbacks.

Mărchidan, A., (2019, June). More technologized is not more educated. Paper presented at the 11th International Conference on Electronics, Computers and Artificial Intelligence (ECAI), Pitesti, Romania. https://doi.org/10.1109 /ECAI46879.2019.9041993

McGinty, E. E., Presskreischer, R., Anderson, K. E., Han, H., \& Barry, C. L. (2020). Psychological distress and COVID-19related stressors reported in a longitudinal cohort of US adults in April and July 2020. JAMA, 324(24), 2555-2557. https://doi.org/10.1001/jama.2020.21231

Mueller, P. A., \& Oppenheimer, D. M. (2014). The pen is mightier than the keyboard: Advantages of longhand over laptop note taking. Psychological Science, 25(6), 1159-1168. https://doi.org/10.1177/0956797614524581

Newport, C. (2016). Deep work: Rules for focused success in a distracted world. New York, NY: Grand Central Publishing

Osman, M. E., \& Hannafin, M. J. (1994). Effects of advance questioning and prior knowledge on science learning. The Journal of Education Research, 88(1), 5-13. https://doi.org /10.1080/00220671.1994.9944829

Oswald, T. K., Rumbold, A. R., Kedzior, S. G. E., \& Moore, V. M. (2020) Psychological impacts of "screen time" and "green time" for children and adolescents: A systematic scoping review. PLoS ONE, 15(9), e0237725. https://doi.org/10.1371 /journal.pone.0237725

Patel, A. V., Maliniak, M. L., Rees-Punia, E., Matthews, C. E., \& Gapstur, S. M. (2018). Prolonged leisure time spent sitting in relation to cause-specific mortality in a large US cohort. American Journal of Epidemiology, 187(10), 2151-2158, https://doi.org/10.1093/aje/kwy125

Peper, E. (2021). Resolve eyestrain and screen fatigue. Well Being Journal, 30, 24-28.

Peper, E., \& Harvey, R. (2018). Digital addiction: Increased loneliness, anxiety, and depression. NeuroRegulation, 5(1), 3-8. https://doi.org/10.15540/nr.5.1.3

Peper, E., Harvey, R., \& Faass, N. (2020). Tech Stress. How technology is hijacking our lives, strategies for coping, and pragmatic ergonomics. Berkeley, CA: North Atlantic Books.

Peper, E., Harvey, R., Mason, L., \& Lin, I.-M. (2018). Do better in math: How your body posture may change stereotype threat response. NeuroRegulation, 5(2), 67-74. https://doi.org $/ 10.15540 / \mathrm{nr} .5 .2 .67$

Peper, E., \& Lin, I.-M. (2012). Increase or decrease depression: How body postures influence your energy level. Biofeedback, 40(3), 126-130. https://doi.org/10.5298/1081-5937-40.3.01

Peper, E., Lin, I-M., Harvey, R., \& Perez, J. (2017). How posture affects memory recall and mood. Biofeedback, 45(2), 36-41. https://doi.org/10.5298/1081-5937-45.2.01

Peper, E., \& Yang, A. (in press). Beyond Zoom fatigue: Reenergize yourself and improve learning. Academia Letters.

Porges, S. W. (2017). The pocket guide to the polyvagal theory: The transformative power of feeling safe. New York, NY: W. W. Norton \& Company.

Purdy, K. (2020, April 21). How to pull off a professional video call from home. New York Times Wirecutter. https://www.nytimes.com/wirecutter/blog/professional-videocall-from-home/

Roberts, F., Margutti, P., \& Takano, S. (2011). Judgments concerning the valence of inter-turn silence across speakers of American English, Italian, and Japanese. Discourse Processes, 48(5), 331-354. https://doi.org/10.1080 10163853X.2011.558002

Rubinstein, P. (2020, November 5). Asynchronous video interviews: The tools you need to succeed. BBC Remote Control. https://www.bbc.com/worklife/article/20201102- 
asynchronous-video-interviews-the-tools-you-need-tosucceed

Schneider, M. (2016). Vision for life, revised edition: Ten steps to natural eyesight improvement. Berkeley, CA: North Atlantic Books.

Solis, B. (2019). How managers can help workers tackle digital distractions. MIT Sloan Management Review, 60(4), 1-3. Retrieved from https://sloanreview.mit.edu/article/howmanagers-can-help-workers-tackle-digitaldistractions/?gclid=CjwKCAiA25v_BRBNEiwAZb4ZRulmrOA9EtQgRLI9FXmmALLPdMAjaFDDVAJSpwo7ta8vE PLW147XRoCmO8QAvD BwE

Stamatakis, E., Gale, J., Bauman, A., Ekelund, U., Hamer, M., \& Ding, D. (2019). Sitting time, physical activity, and risk of mortality in adults. Journal of the American College of Cardiology, 73(16), 2062-2072. https://doi.org/10.1016 /j.jacc.2019.02.031

Tronick, E. [UMass Boston]. (2009, November 30). Still face experiment: Dr. Edward Tronick. [Video]. YouTube. https://youtu.be/apzXGEbZht0
Tronick, E., Adamson, L. B., Als, H., \& Brazelton, T. B. (1975, April). Infant emotions in normal and pertubated interactions. Paper presented at the biennial meeting of the Society for Research in Child Development, Denver, CO.

Wilson, V. E., \& Peper, E. (2011). Athletes are different: Factors that differentiate biofeedback/neurofeedback for sport versus clinical practice. Biofeedback, 39(1), 27-30. https://doi.org /10.5298/1081-5937-39.1.01

Yalçin, I., Özkurt, B., Özmaden, M., \& Yagmur, R. (2020). Effect of smartphone addiction on loneliness levels and academic achievement of $z$ generation. International Journal of Psychology and Educational Studies, 7(1), 208-214. https://doi.org/10.17220/ijpes.2020.01.017

Received: January 01, 2021

Accepted: January 12, 2021

Published: March 29, 2021 